\title{
Impact of new health care policies on the quality of acute myocardial infarction treatment in Swiss hospitals: A before and after observational study
}

\author{
Corine Mouton Dorey*1, Milo Alan Puhan ${ }^{2}$, Nikola Biller-Andorno ${ }^{1}$ \\ ${ }^{1}$ Institute of Biomedical Ethics and History of Medicine (IBME), University of Zurich, Zurich, Switzerland \\ ${ }^{2}$ Epidemiology, Biostatistics and Prevention Institute, University of Zurich, Zurich, Switzerland
}

Received: December 7, 2015

Accepted: February 1, 2016

Online Published: February 20, 2016

DOI: $10.5430 /$ jha.v5n3p10

URL: http://dx.doi.org/10.5430/jha.v5n3p10

\begin{abstract}
Objective: Following a revision of the Swiss Federal Health Insurance Act, the regional hospital planning structure was modified and the hospital financing organized at a national level with the use of diagnosis related groups (SwissDRGs). The aim of this observational study was to determine in an independent way the initial impact of these changes on the quality of hospital treatment, with patients hospitalized for Acute Myocardial Infarction (AMI) being the chosen study group.

Methods: We used prospective data from a Swiss clinical registry for AMI. The quality was measured based on the adherence to 10 evidence-based performance indicators for AMI treatment, and on the evaluation of in-hospital outcomes (mortality, complications, length of hospital stay [LOS]) globally and for seven pre-defined vulnerable subgroups. The study compared patient-based data before (2011) and after (2012) the implementation of the reform.

Results: The study included 33 matched hospitals, and compared the AMI treatment of 2,491 patients in 2011 (before) and 2,544 in 2012 (after the hospital reform). No significant changes in the evidence-based performance indicators were observed, but an on average one day reduction in the LOS and worse outcomes in one of the pre-defined group of patients were found. The issue of how the clinical team achieved these results was not directly explored due to the underlying registry's unalterable structure.

Conclusions: One year after the implementation of a new hospital financing system in Switzerland, the quality of treatment delivered to patients hospitalized for AMI was maintained overall. The worse in-hospital mortality in one pre-defined vulnerable subgroup could reflect the emergence of difficulties for clinical teams to cope with patients demanding extra care and time. Further investigation is warranted.
\end{abstract}

Key Words: Hospital medicine, Quality measurement, Health policy, Evidence-based medicine, Clinical registries

\section{INTRODUCTION}

Healthcare systems differ worldwide but they all share the common aims of high quality and cost containment, which in turn leads to a need for reforms and for an increased accountability to monitor and evaluate health care changes and disease management. The recent revision of the Swiss Fed- eral Health Insurance Act was planned to both contain hospital costs and guarantee hospital healthcare quality, whilst respecting the three main principles of effectiveness, adequacy and economical efficiency, as laid down by the law. ${ }^{[1]}$ Switzerland was therefore a good proxy for the evaluation of healthcare quality under cost constraints.

*Correspondence: Corine Mouton Dorey; Email: corine.moutondorey @uzh.ch; Address: Institute of Biomedical Ethics and History of Medicine (IBME), University of Zurich, Zurich, Switzerland. 
Table 1. Reform of hospital financing in Switzerland ${ }^{[1]}$

Common features of Swiss hospital financing before and after the reform implementation

- Universal basic health insurance (UHI) compulsory for each Swiss resident, federal competence.

- Multiple competitive Swiss health insurers for UHI.

- Private complementary insurers.

- Cantonal (i.e. regional) competence for healthcare planning.

- No free choice of doctor in hospital.

- Health services not covered by UHI: payments by patients and private insurers.

\begin{tabular}{l|l} 
Main UHI financial aspects before January 2012 & Main UHI financial aspects from January 2012 \\
\hline Cantonal planning
\end{tabular}

- Cantonal competence.

- Establishment of a cantonal list of public and subsidized hospitals eligible for cost reimbursement.

- Choice of hospital: free choice limited to hospitals enlisted on the cantonal list of the resident.

- Cost allocation:

- Cantonal listed hospitals: Minimum of 50\% at cantonal level, remaining cost paid by $\mathrm{UHI}$.

- Cantonal non-listed hospitals: payments by patients and private insurers.

- Hospitals in other cantons: full payments by patients and private insurers (except for extra-cantonal hospitals enlisted in the cantonal list and in a few medically justified exceptions).

\section{Payment model for health services and structure}

- Collectively negotiated between hospitals and health insurers and approved by the respective canton at individual cantonal level.

- Daily price, fee-for-services, AP-DRGs, or mixes of them.

- Infrastructure investments managed separately from health services payment.

\section{Challenges}

- Discriminatory cantonal allocation of costs for citizens with complementary private insurances compared to citizens with UHI only (judicial judgment).

- Outside of a few exceptions, no free country-wide choice of hospital.

- Limited availability of national standards to compare hospital services between cantons.

- Limited cost transparency reported at insurers' level.

- Inadequate dual financing of hospital investment and services at cantonal level.

- Difficulties in containing hospital costs.
- Cantonal competence, but economics, infrastructure and quality standards for hospital selection are defined at federal level.

- The cantonal list of eligible institutions for cost reimbursement includes not only public and subsidized hospitals, but also private hospitals and potentially hospitals from other cantons.

- Choice of hospital under UHI: free choice for the whole of Switzerland, amongst the list of indexed hospitals.

- Cost allocation:

- Cantonal listed hospitals: Minimum of 55\% at cantonal level, maximum of $45 \%$ for $\mathrm{UHI}$.

- Cantonal non-listed hospitals: payments by patients and private insurers or if they have signed a contract with UHI, UHI contributes up to $45 \%$.

- Listed hospitals in other cantons: reimbursement based on the residential cantonal prices. Potential surcharges paid by patients and private insurers.

- Collectively negotiated between hospitals and health insurers and approved at national level.

- Based on Diagnosis Related Groups (SwissDRGs) for somatic acute care.

- SwissDRGs' national cost-weights applied to hospital basis price.

- Infrastructure investments included in SwissDRGs.

- Who pays the costs in excess of SwissDRGs reimbursement rates? Not the insurers ( $\max 45 \%$ ), therefore the institutions' owner? Canton? Need to close or restructure hospitals?

- Threat to quality of health services and professional practice due to cost pressure from SwissDRGs.

- Risk of under-investment.

- Insurers able to challenge SwissDRGs coding and reimbursement levels, potentially delaying payment to hospitals.

- Need to establish evidence of improved hospital economics, access and quality.
The legal changes in Switzerland were implemented in 2012 and involved two sets of measures: A new cantonal hospital planning and the introduction of a payment model based on national diagnosis related groups (SwissDRGs). Table 1 summarizes the main features of the Swiss universal health insurance (UHI) for hospitals and the modifications due to the hospital financing reform. Some cantons in Switzerland have been working with DRGs (APDRGs) before 2012. SwissDRGs, however, are based on an adapted version of the German DRGs, which were considered to be very detailed, 
with a high level of precision for comorbidities and case severity. Furthermore, as Switzerland is a small country with German being the most widely spoken language, it was more cost effective to take over the existing field-tested German system.

The intent of the national harmonization was to compare and control costs while guaranteeing health care quality, but to date no evidence has been provided to support this claim. There is as yet no national center for health care quality in Switzerland and no independent program to assess the impact of governmental health care reforms on hospital clinical pathways. Swiss health care professionals were questioning the new hospital policies, which could lead to a reduction in the quantity of care for a standard case, to premature patient discharges, and a decrease in the quality of hospital treatment. Furthermore, patients requiring more intensive care could be the most vulnerable.

The aim of this study was to assess the quality of a routine hospital treatment, with independently recorded evidencebased indicators and outcomes, in a comparative study before and after the introduction of this Swiss national reform. The results were also contributing to a multi-disciplinary project assessing the impact of the reform on patient care and professional practice. ${ }^{[2]}$

\section{MeTHODS}

The study was performed in order to collect prospectively the data from the period before the implementation of the reform, and used comparable indicators before and after the changes. Moreover, the study design had to integrate the constraints of the absence of a control group and the funding period limited to 3 years.

\subsection{Research strategy}

The first step was to identify the agents concerned by the new reimbursement policy and to define the types of measurement. ${ }^{[3]}$ Hospitals were the agents, and the measurement was based on the implementation of evidence-based recommendations for patients for a given disease. There are many ways of measuring healthcare quality; ${ }^{[4]}$ coded administrative data and Inpatient Quality Indicators (IQI) are currently used, ${ }^{[5]}$ but they are linked to the coding guidelines and regulations of the DRGs themselves, ${ }^{[6]}$ with a possible self-preference bias. In addition, the importance of an independent evaluation of government-led reforms has been emphasized. ${ }^{[7]}$ Thus, these administrative data and IQI were not considered suitable for this study.

The decision was thus to develop a quality measurement based on evidence-based recommendations and observational data in the field of acute myocardial infarction (AMI). First, coronary artery disease is associated with a high burden of disease and benefits from long-standing international research and guidelines. ${ }^{[8]}$ These evidence-based recommendations highlight critical clinical care processes to ensure quality in the treatment of AMI patients. ${ }^{[9]}$ Second, adherence to evidence-based recommendations can be measured with observational data, ${ }^{[10]}$ and clinical registries are examples of observational data supporting quality improvement for a clinical condition, diagnostic, procedure or therapy. ${ }^{[11]}$ Third, there was an ongoing clinical registry for AMI in Switzerland, registered at ClinicalTrials.gov and approved by the Supra-Regional Ethics Committee for Clinical Studies, the Swiss Board for Data Security, and the Cantonal Ethics Commissions. ${ }^{[12]}$

\subsection{Access to data and cooperation process}

An agreement was signed at the beginning of 2011 with the registry steering committee for the 3-year research period. It permitted the secondary use of registry data for the years 2010, 2011 and 2012, but not an alteration of the primary structure or sampling design of the registry itself. The participating hospitals owned the data and data could not be disclosed to other parties or published without prior consent of the steering committee. It was agreed that registry data were strictly confidential and that hospital names had to remain anonymous. Patient data were already de-identified in the registry.

The presence of the study researcher in the registry data center allowed an in-depth understanding of the production and use of the registry data, and has thus facilitated transparency and trust. The analysis of data developed in the study was different from the registry's usual analyses. In the registry, the analysis took place on the basis of patient cases; matching hospitals over the years was not required. In our study, the matching units were the hospitals and as a consequence, patients from hospitals, which entered or left the registry in one of the 2-year periods of study, were excluded. Furthermore our study considered performance indicators with different appropriate denominators. The registry analysis concerned a larger and expandable number of variables and could include data from several previous years. Despite these different approaches to clinical data, the cooperation process led the registry's steering committee to support study disclosure.

\subsection{Development of the measurements based on evidence-based recommendations}

Our study drew on international evidence-based recommendations for AMI treatment with predominant class and level of evidence IA or IB. ${ }^{[13-19]}$ The 2010 retrospective registry 
data were used to adjust the measurement set to the existing registry structure. In 2010, 2275 AMI patients were included in the registry by 39 hospitals and amongst them 9 had a round the clock catheter laboratory (CathLab) service available. Some possible indicators were not developed because adequate variables were not at that time collected in the registry (e.g. initial heparin dose, adult smoking cessation advice) or not systematically controlled (e.g. high technology interventions for coronary vessels).

Other performance indicators were disregarded because of missing or implausible data at a rate $\geq 5 \%$ : these were mainly time indicators such as time from symptom onset to hospital admission in patients transferred from/to hospitals not participating in the registry, or in NSTEMI patients (without ST elevation at the initial ECG) presenting usually with a less straightforward diagnosis of AMI. For the purpose of transparency, delays from symptom onset to hospital admission are shown as baseline characteristics, but not used as performance indicators.

Vital signs at admission are also reported as baseline characteristics only, because these data were not audited nor linked to documented clinical shock. Only resuscitation prior to admission was a controlled reported item. Risk factors were identified from the anamnesis section of the questionnaire. For instance a diagnosis of diabetes was identified from the data reported under the headings Charlson index, risk factors and regular medical treatment. Missing data exceeded 5\% for some items such as smoking habits, body mass index or dyslipidemia, and was distributed unequally across hospitals with no possibility to adjust them with a proper weighting. These variables are shown as descriptive baseline but cannot be used for group comparison. For the selected variables to be reported and used as indicators, the measurement set retained for the study had to achieve a rate of less than $3 \%$ missing or implausible data from each participating hospital.

\subsection{Measurement set description}

The set combines ten performance indicators of adherence to evidence-based recommendations, in-hospital outcomes and an evaluation of access to care for pre-defined patient subgroups. Table 2 details the measurement set.

In this study, primary percutaneous coronary intervention (PPCI) refers to balloon angioplasty, with or without stenting, undertaken as the primary reperfusion strategy for AMI without previous or concomitant thrombolytic therapy and performed within 24 hours following hospital admission. Left ventricular systolic dysfunction was defined as the left ventricular ejection fraction $<50 \%$ measured by angiography or $<40 \%$ measured by cardiac echography.
In hospital outcomes included all-cause mortality, major adverse cerebrovascular and cardiac events (MACCE), and the length of hospital stay (LOS) measured in days: median, (IQR $25^{\text {th }}$ and $75^{\text {th }}$ percentiles). Moreover, the following seven subgroups were defined a priori as vulnerable because they represent patients, who may have had a less straightforward diagnosis, required more intensive care or where delays to hospital admission may have been more frequent. These are: advanced age over 75 years, ${ }^{[20]}$ female gender, ${ }^{[21]}$ AMI related cardiac insufficiency at admission defined with Killip classes 3 or $4,{ }^{[22]}$ existence of comorbidities measured by the Charlson comorbidities index (CCI) and more specifically histories of diabetes or renal insufficiency. ${ }^{[23]}$ We added the socio-economic factor "basic insurance coverage only" for patients only covered with the UHI (Universal Health Insurance), additional private and semi-private insurances only being paid by wealthier patients.

\subsection{Implementation of the before and after study}

The measurement set was applied to prospectively collected data to compare the quality of treatment delivered to AMI patients before (2011) and after (2012) the hospital payment changes. The study included all patients from the national clinical registry i.e. AMI patients hospitalized within the first 24 hours of symptoms onset, and defined as STEMI or NSTEMI by characteristic symptoms and/or ECG changes, and cardiac marker elevation. Moreover as we wanted to match hospitals before and after the reform, only patients included by the hospitals that participated in the registry in both years 2011 and 2012 were considered for the analysis. We considered patient-based data in preference to admissionbased data; patient-based data follow patients across hospitals and exclude double counting the same patient in the case of hospital transfer.

\subsection{Statistical analysis}

Data are presented as a proportion of valid cases for discrete variables, as means \pm 1 standard deviation for normally distributed continuous variables and as medians with IQR (25\% and $75 \%$ percentiles) for non-normally distributed continuous variables. Each individual adherence rate to guidelines was calculated as a performance ratio of valid cases over eligible patients for the indicator. Comparisons before (2011) and after (2012) concerned independent patients from matched hospitals, and were compared using the Student's two-tailed unpaired $t$ test for continuous normally distributed variables, the Mann-Whitney $U$ test for continuous non-normally distributed variables and the Pearson chi square test for categorical variables. A probability value of $<.05$ was considered significant. 
Table 2. Measurement set for patients hospitalized within 24 hours of acute myocardial infarction

\begin{tabular}{|c|c|c|}
\hline Measure Name & Eligible patients $^{*}$ & Measure type \\
\hline \multicolumn{3}{|c|}{ A. Adherence rate to evidence-based recommendations in \% } \\
\hline 1. Immediate triple therapy (ASA, $\left.\mathrm{P}_{2} \mathrm{Y}_{12}, \mathrm{AC}\right)$ & Alive in the first $24 \mathrm{~h}$ & Treatment \\
\hline 2. Primary PCI performed: PPCI & All & Treatment, diagnosis \\
\hline $\begin{array}{l}\text { 3. Evaluation of LVEF (with angiography or } \\
\text { echography) }\end{array}$ & Alive at discharge & Intermediate outcome, diagnosis \\
\hline 4. DAPT (ASA, P2 $\mathrm{Y}_{12}$ ) at discharge & Alive at discharge & Treatment \\
\hline 5. Beta-blocker at discharge & Alive at discharge & Treatment \\
\hline 6. Statins at discharge & Alive at discharge & Treatment \\
\hline 7. ACEI or ARB for LVSD, at discharge & Alive at discharge and LVSD & Treatment \\
\hline 8. Cardiac rehabilitation patient referral & $\begin{array}{l}\text { Alive at discharge and no transfer to other hospitals or } \\
\text { nursing homes }\end{array}$ & Patient education \\
\hline 9. Door-to-balloon time $\leq 90$ minutes & $\begin{array}{l}\text { STEMI, PPCI, no symptoms onset in hospital, } \\
\text { no transfer from/to non participanting registry hospitals }\end{array}$ & Treatment, process \\
\hline 10. Time to reperfusion $\leq 12$ hours & $\begin{array}{l}\text { STEMI, PPCI, no symptoms onset in hospital, } \\
\text { no transfer from/to non participanting registry hospitals }\end{array}$ & Treatment, process \\
\hline \multicolumn{3}{|l|}{ B. In-hospital outcomes } \\
\hline 1. All cause mortality, adjusted & All & Outcome \\
\hline 2. MACCE, adjusted & All & Composite outcome \\
\hline 3. Length of hospital stay, days (median, IQR) & All & Process, outcome \\
\hline \multicolumn{3}{|l|}{ C. Access to care/clinically vulnerable patients } \\
\hline 1. Age $>75$ years & All & Admission rate $\%$. \\
\hline 2. Female gender & All & \multirow{6}{*}{$\begin{array}{l}\text { In-hospital outcomes. } \\
\text { Adherence to guidelines when } \\
\text { relevant. }\end{array}$} \\
\hline 3. Killip 3 and 4 at admission & All & \\
\hline 4. Charlson Comorbidities Index $(\mathrm{CCI}) \geq 2$ & All & \\
\hline 5. Diabetes & All & \\
\hline 6. Renal insufficiency moderate $\&$ severe & All & \\
\hline 7. Basic insurance coverage only & All & \\
\hline \multicolumn{3}{|c|}{$\begin{array}{l}\text { * Eligible patients: denominator of the ratio for adherence to guidelines calculation, or for admission rate. AMI: acute myocardial infarction; AC: anticoagular } \\
\text { therapies; ACEI: angiotensin-converting enzyme inhibitor; ARB: angiotensin receptor blocker; ASA: aspirin; CCI: weighted Charlson index for comorbiditie } \\
\text { DAPT: dual antiplatelet therapy; IQR: interquartile range; LVEF: left ventricular ejection fraction; LVSD: left ventricular systolic dysfunction; MACCE: maj } \\
\text { adverse cardiac- and cerebrovascular events; NSTEMI AMI without ST elevation on the initial electrocardiogram; P2 } \mathrm{Y}_{12} \text { indirect (thienopyridines) and dire } \\
\text { P2Y } \mathrm{Y}_{12} \text { inhibitors; (P) PCI (primary) percutaneous coronary intervention; STEMI AMI with segment ST-elevation or new left bundle branch block on the initi } \\
\text { electrocardiogram }\end{array}$} \\
\hline
\end{tabular}

Mortality and MACCE were adjusted for differences in baseline characteristics known to influence survival and admission year. We used a logistic regression model with inhospital mortality (or MACCE) as a dependent variable and the following independent variables: year of admission as the variable of interest, and age, sex, resuscitation before admission, diagnosis STEMI/NSTEMI, Killip class 3 or 4 at admission and comorbidities as characteristics known for their strong impact on in-hospital mortality (heart failure, diabetes, renal insufficiency or metastatic tumors) and thus acting as potential confounders. ${ }^{[23]}$ The odd ratios (ORs) were presented with 95\% CI. The SPSS software (SPSS Inc., Chicago, Illinois; Version 21.0) was used for all statistical analyses.

\section{RESUlts}

The clinical registry enrolled 5,935 patients (2,491 in 2011, 2,544 in 2012) whose data were available at the registry data center at the end of June 2013. The data were accessed and controlled for our secondary analysis: 5,035 patients met the study inclusion criteria and the remaining 900 patients were excluded for the following reasons: double entries ( $n=142$ patients transferred and included both in hospitals with and without CathLab for the same AMI); patients who had PCI before admission in a non-reporting hospital $(n=92)$; patients from hospitals that did not participate in both years of the registry ( $n=666$ in total, divided in $\mathrm{n}=450$ for participation in 2011 only, $\mathrm{n}=216$ for participation in 2012 only). 
Table 3. Baseline characteristics of patients admitted with AMI according to year of admission

\begin{tabular}{|c|c|c|c|}
\hline & 2011 & 2012 & $p$-value \\
\hline $\mathrm{N}$ patients ( $\mathrm{N}$ hospitals) & $2,491(33)$ & $2,544(33)$ & \\
\hline $\mathrm{N}$ patients $(\%)$ from hospitals with CathLab $(\mathrm{N}=12)$ & $1,834(73.6)$ & $1,981(78.1)$ & \\
\hline $\mathrm{N}$ patients $(\%)$ from hospitals without CathLab $(\mathrm{N}=21)$ & $657(26.4)$ & $563(21.9)$ & \\
\hline Transfers from non-participating hospitals & $610(24.5)$ & $636(25.0)$ & \\
\hline PPCI & $1,760(70.7)$ & $1,840(72.3)$ & .416 \\
\hline Age (years) & $67.1 \pm 13.1$ & $66.6 \pm 13.0$ & .231 \\
\hline Male gender & $1,807(72.5)$ & $1,883(74.0)$ & .237 \\
\hline Delay symptoms onset to admission & 1,667 & 1,808 & \\
\hline - hours: minutes (median, IQR 25, 75 quartiles) & $3: 30(1: 37,8: 45)$ & $3: 06(1: 30,8: 30)$ & .264 \\
\hline Diagnosis STEMI & $1,295(52.0)$ & $1,320(51.9)$ & .943 \\
\hline Resuscitation prior admission & $123(4.9)$ & $153(6.0)$ & .093 \\
\hline Symptoms at admission: typical & $2,035(81.7)$ & $2,000(78.6)$ & .022 \\
\hline \multicolumn{4}{|l|}{ Vital signs at admission: } \\
\hline - Systolic blood pressure $<100 \mathrm{mmHg}$ & $145(5.9)$ & $182(7.3)$ & .051 \\
\hline - Heart rate $>100$ beats & $269(11.0)$ & $240(9.6)$ & .125 \\
\hline \multicolumn{4}{|l|}{ Heart rhythm: } \\
\hline - Sinus rhythm & $2,236(89.8)$ & $2,303(90.5)$ & .666 \\
\hline - Atrial fibrillation & $133(5.3)$ & $137(5.4)$ & \\
\hline Killip class: & 2,483 & 2,535 & .866 \\
\hline$\bullet 1$ & $2,032(81.8)$ & $2,085(82.2)$ & \\
\hline$\cdot 2$ & $238(9.6)$ & $247(9.7)$ & \\
\hline$\cdot 3$ & $83(3.3)$ & $75(3.0)$ & \\
\hline - 4 & $130(5.2)$ & $128(5.1)$ & \\
\hline \multicolumn{4}{|l|}{ Risk factors: } \\
\hline - Current smoker & $855(38.4)$ & $872(38.5)$ & .904 \\
\hline - History of Dyslipidemia & $1,195(54.3)$ & $1,355(58.9)$ & .002 \\
\hline - History of Hypertension & $1,518(64.2)$ & $1,519(62.2)$ & .160 \\
\hline - History of Diabetes & $506(21.4)$ & $501(20.3)$ & .341 \\
\hline - Obesity Body Mass Index $>30$ & $465(22.4)$ & $477(21.5)$ & .465 \\
\hline History of MI or stable angina & $830(34.3)$ & $812(32.8)$ & .275 \\
\hline \multicolumn{4}{|l|}{ Vulnerable sub-groups: } \\
\hline - Age $>75$ years & $795(31.9)$ & $758(29.8)$ & .104 \\
\hline - Female gender & $684(27.5)$ & $661(26.0)$ & .237 \\
\hline - Killip classes 3 and 4 at admission & $213(8.6)$ & $203(8.0)$ & .464 \\
\hline - Diabetes (patient history) & $506(21.4)$ & $501(20.3)$ & .341 \\
\hline - Renal insufficiency & $224(9.2)$ & $230(9.2)$ & .990 \\
\hline - $\mathrm{CCI} \geq 2$ & $627(25.2)$ & $645(25.4)$ & .881 \\
\hline - Basic insurance coverage only & $1,693(71.6)$ & $1,859(75.4)$ & .003 \\
\hline
\end{tabular}

Note. Values are mean $\pm S D$ (standard deviation), median (IQR), N/total (\%), or N. MI: (acute) myocardial infarction; CathLab a round the clock catheter laboratory service available; CCI: Charlson index for comorbidities; IQR: interquartile range; PPCI: primary percutaneous coronary intervention; NSTEMI AMI without ST elevation on the initial electrocardiogram; STEMI AMI with segment ST-elevation or new left bundle branch block on the initial electrocardiogram

As shown in Table 3, patient baseline characteristics such as age, gender, AMI diagnosis, hemodynamic status at entry, major risk factors, and degree of comorbidities measured by the Charlson index were not statistically significantly different between the 2 years of admission; however, a higher number of patients with "basic insurance coverage only" was recorded in 2012.

Published by Sciedu Press
The results showed no statistically significant differences in the quality of treatment for eight indicators of adherence to evidence-based recommendations. The indicators 1 and 4 could not appropriately record the prescription of a new direct $\mathrm{P}_{2} \mathrm{Y}_{12}$ inhibitor treatment introduced onto the market at the end of 2011; the registry questionnaire was modified in October 2011 to collect this new item but the changes were 
implemented at an unequal pace amongst hospitals; therefore, the observed difference between 2011 and 2012 cannot be taken into consideration statistically nor clinically (see Table 4).

Overall, the adjusted rates of mortality (OR 1.061, 95\% CI 0.784-1.435) and MACCE (OR 0.915, 95\% CI 0.704-1.188) did not show statistically significant changes in $2012 \mathrm{vs}$. 2011. There was a statistically significant reduction of 1 day in the median LOS in 2012 compared to 2011, in all patients and in STEMI patients (median of 5 days [IQR 2,8] in 2011 to 4 days [IQR 2,7] in 2012, $p=.001$ ); vulnerable subgroups were not discharged earlier.

The analyses of the seven vulnerable subgroups showed that one subgroup, the patients with Killip class 3 or 4 at admission, had statistically significant worse in-hospital outcomes. After adjustment for age and gender, the results confirmed that year of admission had influenced in-hospital mortality in these patients (OR 1.60, 95\% CI 1.06-2.41) and in-hospital MACCE (OR 0.658, 95\% CI 0.439-0.987).

Table 4. Impact of admission year on adherence rate to evidence-based recommendations in AMI patients

\begin{tabular}{|c|c|c|c|}
\hline Adherence rate to evidence-based recommendations in \% (N) & 2011 & 2012 & $p$-value \\
\hline 1. Immediate triple therapy (ASA, $\left.\mathrm{P} 2 \mathrm{Y}_{12}, \mathrm{AC}\right)$ & $86.6(1,774)$ & $75.7(1,875)$ & $<.001^{*}$ \\
\hline 2. Primary PCI performed: PPCI & $73.2(1,730)$ & $74.8(1,797)$ & .402 \\
\hline 3. Evaluation of LVEF & $84.2(1,991)$ & $85.1(2,043)$ & .406 \\
\hline 4. DAPT (ASA, P2 $\left.\mathrm{Y}_{12}\right)$ at discharge & $93.7(2,041)$ & $87.0(2,079)$ & $<.001^{*}$ \\
\hline 5. Beta-blocker at discharge & $74.2(1,731)$ & $72.1(1,730)$ & .096 \\
\hline 7. ACEI or ARB for LVSD, at discharge & $85.7(654)$ & $85.9(639)$ & .923 \\
\hline 8. Cardiac rehabilitation patient referral & $43.7(750)$ & $45.3(786)$ & .330 \\
\hline 9. Door-to-balloon time $\leq 90$ minutes & $62.1(347)$ & $65.3(416)$ & .246 \\
\hline 10. Time to reperfusion $\leq 12$ hours & $83.9(390)$ & $85.2(459)$ & .574 \\
\hline
\end{tabular}

\footnotetext{
${ }^{*}$ The differences in the indicators 1 and 4 are due to the introduction of a new antiplatelet drug at the end of 2011. No weighted adjustment was statistically possible for the 33 hospitals. AMI: acute myocardial infarction; AC :anticoagulant therapies; ACEI angiotensin-converting enzyme inhibitor; ARB angiotensin receptor blocker; ASA: aspirin; DAPT: dual antiplatelet therapy; LVEF left ventricular ejection fraction; LVSD: left ventricular systolic dysfunction; P2Y 12 indirect (thienopyridines) and direct P2 $\mathrm{Y}_{12}$ inhibitors; PCI: percutaneous coronary intervention
}

\section{DISCUSSION}

The customized use of clinical registry data enabled a clinical assessment of hospital treatment quality independent from administrative data and SwissDRGs. Despite the limited time available for our research before the introduction of the reform, it was possible to collect prospective data before the hospital payment changes and to perform a before and after observational study.

\subsection{Comments on the results}

The 33 study hospitals were distributed across Switzerland and represented about $30 \%$ of all AMIs. ${ }^{[24]}$ The higher number of patients with "basic insurance cover only" in 2012 could be a simple consequence of a reclassification of patients following the new hospital planning. Baseline characteristics in 2011 and 2012 confirmed the absence of relevant differences in the clinical profile of the two populations in comparison.

The results showed that the quality of treatment for AMI patients was maintained overall after the introduction of new policies and SwissDRGs. However, this finding needs to be interpreted cautiously. First, it is not clear how the clinical team has achieved this preservation of quality and whether this result will hold over time. Additional studies, which focus on the behavior of healthcare professionals, would be useful to help interpret these results because both medical and non-medical staff are key players for implementing evidencebased recommendations. ${ }^{[25]}$ Moral distress could develop following challenging or constraining conditions of work. ${ }^{[26]}$ This is all the more important, as a recent mixed-method study emphasized the importance of an integrated approach to quality management. ${ }^{[27]}$ Concerning the reduction of the LOS, it is recognized that LOS influences substantially total hospital expenses. ${ }^{[28]}$ Nevertheless, if this result is confirmed over time, it still has to be interpreted with prudence as a positive impact because waste may not have been reduced, rather it could just represent a shift of activities to the ambulatory sector without any overall cost reduction. The EuroDRG group, who identified the difficulty to match AMI clinical patterns with an appropriate DRGs classification for costs and performance comparison, has already recognized this issue. ${ }^{[29]}$

With regard to the subgroup of patients with Killip class 3 or 4 at admission, their worse in-hospital mortality could reflect 
a stochastic variation, but also the emergence of difficulties for clinical teams to cope with patients demanding extra care and time under cost constraints. Even an incorrectly perceived loss of quality by clinical teams has been associated with an increase of patient mortality. ${ }^{[30]}$

It is interesting to note that the analysis of specific clusters for vulnerable patients has detected changes that would have remained invisible in a solely global quality appraisal. It has already been demonstrated that global health outcomes can mask differences between groups and in particular for the ones vulnerable to inequalities. ${ }^{[31]}$ The DRGs system itself favors a global approach because variations from a standard case are regarded as outliers to be solved by a continuous adjustment. Our study shows that health care quality could be impaired for one vulnerable group. This quality issue is also implicitly recognized at the European level as payment incentives for quality are recommended in order to improve the DRGs system. ${ }^{[32]}$

\subsection{Comments on the study process}

The pioneer aspect in Switzerland of this study is explained by the following factors. First, the absence of a single health insurance provider as well as the legislation on privacy and data protection has limited the development of nationally publicly funded clinical registries. Second, there is as yet no single center for quality and safety of the Swiss health care system; the Swiss Federal Council is currently working on a federal law for such a center. The Swiss Academy of Medical Sciences has been consulted and has emphasized the issues of governance and independence as well as the need for high quality medical registries and measurements. ${ }^{[33]}$

On a more general point of view, the governance and independence of hospital quality evaluation remain important issues. This applies not only to the Swiss Bismarck model of hospital care, but also to countries with a Beveridge model of national healthcare systems, which may have more extensively developed medical databases for quality evaluation but are also heavily dependent on public funding. An independent evaluation of health care quality would support the learning process regarding clinical practice under cost pressures, and encourage the "bottom-up" involvement of clinical teams in discussions pertaining to health care policies.

\subsection{Limitations}

This study has some limitations. First, the main limit came from the time-limited funding of the project, which did not permit pursuing the monitoring after 2013. A prolongation would increase the chance to detect changes in treatment if they occur. Second, the advantage of ready-to-use secondary Published by Sciedu Press data was counterbalanced by the dependence on the underlying clinical registry's unalterable structure. Clinical registries carry a risk of bias through non-consecutive inclusion and confounding factors. The quality of the data recording, the need to include consecutive patients, the necessity of longterm commitment from the participating hospitals and the conduct of regular audits are key elements of registry usefulness. A further limitation came from the impossibility to introduce in this short time period the collection of contraindications to- or patient refusal of- drug treatment, as well as the collection of controlled high-technology data (for instance number and type of stents), patient socio-economic indicators, or satisfaction scales for patients and clinical teams. These limitations identify how challenging it can be to involve clinical registries in quality assessment research. They also indicate directions for improvement such as the implementation of recommendations to promote the quality and social value of clinical registries, and the importance to maintain a good interdisciplinary dialogue for an independent evaluation of hospital quality.

\subsection{Ethical perspective}

The interface between established clinical registries and quality assessment research projects also raises some ethical points of consideration.

Firstly, data ownership and funding can become an issue in the cooperation process, for instance between publicly founded academic projects and privately funded registries. Sustainable funding is a real issue for clinical registries, and fees for data could stimulate fruitful collaboration on health care quality improvement projects. ${ }^{[34]}$ However, this could also lead to moral and legal issues of data ownership, which need to be further explored.

Secondly, data sharing and trust can be difficult to appropriately manage. Secondary analysis of registry data has been reported to be useful to improve patient care, but the absence of a centralized shared repository of data is regarded as a barrier to its development. ${ }^{[35]}$

Thirdly, confidentiality, consent and patient information are important points to be discussed. According to the Swiss law for human research, ethical review committees waived patient informed consent for most of the registries dealing with anonymous data. ${ }^{[36]}$ Consequently, patients are usually not informed of the possible secondary use of their data for research projects on health care quality and access to care. This may not be a problem as long as there is a clear benefit from the research on health care quality. However, an ethical issue with patient information would emerge more clearly if 
the quality of health care services worsens, or if some groups of patients are stigmatized because they demand more care and thus cost more than the average patient. Better information to patients could help improve transparency in the production and use of data and increase patient's knowledge and agency. As a result, the production and use of observational data could strengthen trustful relationships between health care providers and patients. ${ }^{[37]}$

\section{Conclusion}

Sharing of observational clinical data allowed the realization of this before and after study in order to perform an independent assessment of the impact of new hospital financial policies on the quality of hospital treatment. In the first year following the introduction of the reform, the study showed a reduction of the LOS for AMI patients, but no significant modification of the evidence-based treatment delivered to them. The specific measurements of outcomes in pre-defined sub-groups of patients identified one group, namely those with AMI related cardiac insufficiency at admission, who demonstrated a higher risk of in-hospital complications and mortality between the before and after phases. These findings need to be confirmed over a longer period of time, but can already contribute to the discussion about hospital costs, professional practice constraints, quality of healthcare services and their concomitant evaluation.

\section{Ethical approval}

AMIS Plus Registry had ethical approval from the SupraRegional Ethics Committee for Clinical Studies, the Swiss Board for Data Security, and the Cantonal Ethics Commissions. Trial registration: ClinicalTrials.gov (identifier NCT01305785).

\section{ACKNOWLEDGEMENTS}

All the authors contributed to the study and have read and approved the final version of the manuscript. CMD carried out the study design, the data analysis, and drafted the manuscript. NBA provided advice during the study, helped conceptualize the presentation of the research results, and reviewed the manuscript. MAP supervised the data analysis, helped organize the manuscript and reviewed it.

The authors thank the AMIS Plus registry, the participating hospitals and the AMIS Plus Data Center in Zurich. Data were provided by AMIS Plus registry free of charge. The authors thank Prof. Thomas Zeltner who reviewed the manuscript for the legal aspects of the Swiss hospital financing system described in the introduction and Table 1. CMD was supported by a grant from the Swiss National Science Foundation SNSF in relation to the IDoC project (SNF RSII3_132786).

\section{CONFLICTS OF INTEREST Disclosure}

The authors declare that they have no competing interests.

\section{REFERENCES}

[1] Federal Health Insurance Act of 18 March 1994 (Status as of 1 July 2013): SR 832.10. 1. Message 04.061 about the partial revision of the Federal Health Insurance Act (hospital financing): BBI 2001 5551. OECD Reviews of Health Systems: Switzerland 2011. Available from: http://www.oecd-ilibrary.org/social-i ssues-migration-health/oecd-reviews-of-health-sys tems-switzerland-2011_9789264120914-en

[2] Wild V, Pfister E, Biller-Andorno N. Ethical research on the implementation of DRGs in Switzerland - a challenging project. Swiss Med Wkly. 2012. http://dx. doi : 10.4414/smw . 2012.13610

[3] Arah OA. On the evaluative space for measuring public health performance. The philosophy of public health. Dawson A editor. England: Farnham; 2009. 49-62 p.

[4] Hernandez AF, Fonarow GC, Liang L, et al. The need for multiple measures of hospital quality. Results from the Get With The Guidelines-Heart failure registry of the American heart association. Circulation. 2011; 124: 712-719. http://dx.doi.org/10.1161 /circulationaha.111.026088

[5] Federal Office of Public Health. Topics / Health Insurance: Quality indicators in hospital statistics [cited 2013 Dec 9]. Available from: http://www.bag-anw.admin.ch/kuv/spitalstatisti $\mathrm{k} /$ portal_de.php?navid=qiss
[6] Busse R, Nimptsch U, Mansky T. Measuring, monitoring, and managing quality in Germany's hospitals. Health Aff (Millwood). 2009; 28(2): 294-304. http://dx.doi.org/10.1377/hlthaff .28.2. w294

[7] Sheikh A, Atun R, Bates DW. The need for independent evaluations of government-led health information technology initiatives. BMJ Qual Saf. 2014; 23: 611-613. http://dx.doi.org/10.1136/bmj qs-2014-003273

[8] Nichols M, Townsend N, Luengo-Fernandez R, et al. European Cardiovascular Disease Statistics 2012. European Heart Network, Brussels, European Society of Cardiology, Sophia Antipolis [cited 2013 Dec 9]. Available from: http://www .escardio.org/about/documents/eu-cardiov ascular-disease-statistics-2012.pdf

[9] Krumholz HM, Anderson JL, Bachelder BL, et al. ACC/AHA 2008 performance measures for adults with ST-elevation and non-STelevation myocardial infarction. J Am Coll Cardiol. 2008; 52: 20462099. http://dx.doi.org/10.1016/j.jacc. 2008.10.012

[10] Jernberg T, Johanson P, Held C, et al. Association between adoption of evidence-based treatment and survival for patients with STelevation myocardial infarction. JAMA. 2011; 305(16): 1677-1684. http://dx.doi.org/10.1001/jama.2011.522

[11] Gliklich RE, Dreyer NA. Registries for Evaluating Patient Outcomes: A User's Guide. Agency for Healthcare Research and Quality (US) 
Second edition. Rockville, MD; 2010 [cited 2013 Dec 9]. Available from: http://www.effectivehealthcare.ahrq.gov/index .cfm/search-for-guides-reviews-and-reports/?pageac tion=displayproduct\&productid $=401$

[12] Radovanovic D, Nallamothu BK, Seifert B, et al. Temporal trends in treatment of ST-elevation myocardial infarction among men and women in Switzerland between 1997 and 2011. Eur Heart J Acute Cardiovasc Care. 2012; 1(3): 183-191.

[13] Antman EM, Anbe DT, Armstrong PW, et al. ACC/AHA guidelines for the management of patients with ST-elevation myocardial infarction. Executive summary. J Am Coll Cardiol. 2004; 110: 588-636. ht tp://dx.doi.org/10.1161/01.CIR.0000134791.68010.FA

[14] Antman EM, Hand M, Armstrong PW, et al. 2007 focused update of the ACC/AHA 2004 guidelines for the management of patients with ST-elevation myocardial infarction. Circulation. 2008; 117: 296-329. http://dx.doi.org/10.1016/j.jacc.2007.10.001

[15] Van de Werf F, Bax J, Betriu A, et al. Management of acute myocardial infarction in patients presenting with persistent ST-segment elevation. Eur Heart J. 2008; 29: 2909-2945. http://dx. doi .org /10.1093/eurheartj/ehn416

[16] Anderson JL, Adams CD, Antman EM, et al. ACC/AHA 2007 Guidelines for the management of patients with unstable angina/non-STelevation myocardial infarction: Executive summary. Circulation. 2007; 116: 803-877. http://dx.doi.org/10.1161/CIRCULATI ONAHA. 107.185752

[17] Wijns W, Kohl P, Danchin N, et al. Guidelines on myocardial revascularization. Eur Heart J. 2010; 31: 2501-2555. http://dx. doi .o $\mathrm{rg} / 10.1093$ /eurheartj/ehq277

[18] Wright RS, Anderson JL, Adams CD, et al. 2011 ACCF/AHA focused update of the guidelines for the management of patients with unstable angina/non-ST-elevation myocardial infarction (updating the 2007 guideline). Circulation. 2011; 123: 2022-2060. http://dx.doi.org/10.1161/CIR.0b013e31820f2f3e

[19] Hamm CW, Bassand JP, Agewall S, et al. ESC Guidelines for the management of acute coronary syndromes in patients presenting without persistent ST-segment elevation. Eur Heart J. 2011; 32: 2999-3054. http://dx.doi.org/10.1093/eurheartj/ehr236

[20] Gharacholou SM, Lopes RD, Alexander KP, et al. Age and outcomes in ST-segment elevation myocardial infarction treated with primary percutaneous coronary intervention: findings from the APEX-AMI trial. Arch Intern Med. 2011; 171(6): 559-67. http: //dx.doi.org/10.1001/archinternmed.2011.36

[21] D'Ascenzo F, Gonella A, Quadri G, et al. Comparison of mortality rates in women versus men presenting with ST-segment elevation myocardial infarction. Am J Cardiol. 2011; 107: 651-654. http://dx.doi.org/10.1016/j.amjcard.2010.10.038

[22] Mercado-Martínez J, Rivera-Fernández R, Aguilar-Alonso E, et al. APACHE-II score and Killip class for patients with acute myocardial infarction. Intensive Care Med. 2010; 36(9): 1579-1586. http://dx.doi.org/10.1007/s00134-010-1832-6

[23] Radovanovic D, Seifert B, Urban P, et al. Validity of Charlson Comorbidity index in patients hospitalised with acute coronary syndrome. Insights from the nationwide AMIS Plus registry 2002-2012. Heart. 2014; 100(4): 288-294. http://dx.doi:10.1136/heartjnl-2 013-304588
[24] Insam C, Paccaud F, Marques-Vidal P. Trends in hospital discharges, management and in-hospital mortality from acute myocardial infarction in Switzerland between 1998 and 2008. BMC Public Health. 2013; 13: 270-283. http://dx.doi.org/10.1186/1471-245 $8-13-270$

[25] Widimsky P, Wijns W, Fajadet J, et al. Reperfusion therapy for ST elevation acute myocardial infarction in Europe: description of the current situation in 30 countries. Eur Heart J. 2010; 31: 943-957. http://dx.doi.org/10.1093/eurheartj/ehp492

[26] Fourie C. Moral Distress and Moral Conflict in Clinical Ethics. Bioethics Published Online First: 8 November 2013. http://dx .doi.org/10.1111/bioe.12064

[27] Wagner C, Groene O, Thompson CA, et al. DUQuE quality management measures: associations between quality management at hospital and pathway levels. Int J Qual Health Care. 2014 Apr; 26(Suppl 1): 66-73. http://dx.doi.org/10.1093/intqhc/mzu020

[28] Felder S. The variance of length of stay and the optimal DRG outlier payments. Int J Health Care Finance Econ. 2009; 9: 279-289. http://dx.doi.org/10.1007/s10754-008-9051-1

[29] Quentin W, Rätto H, Peltola M, et al. Acute myocardial infarction and diagnosis-related groups: patient classification and hospital reimbursement in 11 European countries. Eur Heart J. 2013; 34: 1972 1981. http://dx.doi.org/10.1093/eurheartj/ehs482

[30] Tvedt C, Sjetne IS, Helgeland J, et al. An observational study: associations between nurse-reported hospital characteristics and estimated 30-day survival probabilities. BMJ Qual Saf. 2014; 23(9): 757-64. http://dx.doi.org/10.1136/bmjqs-2013-002781

[31] Petticrew M, Whitehead M, Macintyre J, et al. Evidence for public health policy on inequalities: 1 : The reality according to policymakers. J Epidemiol Community Health. 2004; 58: 811-816. PMid: 15365104. http://dx.doi.org/10.1136/jech. 2003.015289

[32] Busse R, Geissler A, Aaviksoo A, et al. Diagnosis related groups in Europe: moving towards transparency, efficiency, and quality in hospitals? BMJ. 2013; 346: f3197. http://dx.doi.org/10.11 $36 / \mathrm{bmj}$. $\mathrm{f} 3197$

[33] Statement of the Swiss Academy of Medical Sciences, in German, dated September 5, 2014. Akademien äussern sich kritisch zum Bundesgesetz über ein Zentrum für Qualität in der OKP [cited 2014 Sep 8]. Available from: http://www. samw. ch/de/Aktuell/New s.html

[34] Bufalino VJ, Masoudi FA, Stranne SK, et al. The American Heart Association's Recommendations for Expanding the Applications of Existing and Future Clinical Registries: A Policy Statement From the American Heart Association. Circulation. 2011; 123(19): 2167-2179. http://dx . doi .org/10.1161/CIR. Ob013e3182181529

[35] Cooke CR, Iwashyna TJ. Using existing data to address important clinical questions in critical care. Crit Care Med. 2013; 41(3): 886896. http://dx.doi.org/10.1097/CCM.0b013e31827bf c3c

[36] Federal Human research Act of 30 September 2011 (status as of 1 January 2014): SR 810.30 .

[37] Ioannidis JP. Informed Consent, Big Data, and the Oxymoron of Research That Is Not Research. Am J Bioeth. 2013; 13/4: 40-42. http://dx.doi.org/10.1080/15265161.2013.768864 